\title{
Insucesso e selecção social na disciplina de Português: o(s) discurso(s) dos professores - uma abordagem interdisciplinar
}

\author{
RUI VIEIRA DE CASTRO e LICÍNIO C. LIMA *
}

\section{INTRODUÇÃO}

No âmbito do estágio integrado da Licenciatura em Ensino de Português-Inglês foi por nós oricntado, em 1985, um Seminário que teve por objecto algumas das formas específicas que as relaçõcs entre cultura, linguagem e curriculum escolar revestem no contcxto português.

O texto que agora se apresenta, na scquência de discussões realizadas e de dados e informações que então recolhemos, pretende constituir-sc como momento de fixação de algumas reflexões e como esboço de possíveis linhas de análise. Não se trata, aqui, de configurar conclusões; antes, é nosso propósito a construção de uma proposta de trabalho cuja validade será estabelecida pcla sua eventual capacidade de gerar e definir trajcctos de investigação.

Este trabalho parte da verificação do carácter duplamente selectivo da disciplina de Português. Por um lado, e em termos absolutos, ela assume mais do que outras disciplinas uma função de seleç̧ão em termos de insucesso escolar; por outro lado, o seu grau de selectividade é desigualmente distribuído pelos alunos consoante a sua «posição social». Esta é uma evidência empírica que encontrámos. Interessou-nos saber de que modo vivem os professores de Português com esta realidade; desde logo, procurando averiguar o peso relativo que atri-

\footnotetext{
* Docentes da Universidade do Minho
}

buem à sua disciplina, seguidamente tentando detectar as razões para justificar aquele peso, depois inquirindo sobre as hipóteses explicativas que eram fornecidas para o elevado grau de insucesso na disciplina, relacionadas primeiro com factores gerais, escolares e sociais, de seguida com factores intrínsecos.

A recolha de dados, o seu tratamento e interpretação foram enquadrados numa determinada perspectiva, que releva da articulação de informações de teor psico-sociológico e linguístico, sobre a relação entre a linguagem, os curricula e as modalidades de cultura que se constituem no grupo social em que são construídos.

Toda a modalidade de cultura representa uma «perspectivaçẵo arbitrária de uma realidade potencial» $\left({ }^{1}\right)$. Sobre esta realidade especializam-se conjuntos de procedimentos de carácter ideológico, moral, estético, etc., que traduzem formas distintas de relação e posicionamento. Neste sentido, as modalidades de cultura são realidades objectiváveis, organizadas sobre um mundo potencial.

Os procedimentos específicos que constituem as modalidades de cultura são operados por grupos cuja coerência pode ser regulada por princípios como a origem social, a localização na hierarquia da organização, o sexo, etc.

As modalidades de cultura são desenhadas por procedimentos sistcmáticos e não pelo conjunto das

(1) BERNSTEIN, B. (1981). «Codes, molalities, and the process of cultural reproduction: A models. Language and Society, (10), p. 339. 
práticas dos agentes. De facto, a variação do contexto de acção e interaç̧ão destes pode traduzir-se em procedimentos distintos.

As relações de classe, entendidas como «desigualdades na distribuição do poder e nos princípios de controlo entre grupos sociais» $\left({ }^{2}\right)$ estabelecem as bases para uma relação hierarquizada das modalidades de cultura e dos seus agentes.

Os grupos e as modalidades de cultura que lhes estão associadas mantêm entre si uma relação conflitual; as instituições (sindicato, escola, etc.), que podem por vezes constituir a sua expressão privilegiada, podem também servir a negociação do poder e do controlo.

No sistema educativo, o curriculum configura-se como organização arbitrária de conteúdos de tal modo que alguns deles têm um estatuto especial relativamente a outros $\left(^{3}\right)$. A título de exemplo atente-se na organização oficial do elenco das disciplinas (não é por acaso que ao Português é conferida sistematicamente a primeira posição), na variação da carga horária (compare-se a carga horária relativa do Português e da Geografia), na frequência com que aparecem no plano curricular (o Português é obrigatório do $7^{\circ}$ ao $11^{\circ}$ anos de escolaridade) ou na sua pertinência em termos de avaliação final do aluno (recorde-se que, por exemplo, a Educação Física e a Religião e Moral não podem determinar a reprovação do aluno). A maior ou menor relevância de alguns conteúdos relativamente a outros traduz uma organização especial da relação entre as modalidades de cultura e a maior ou menor capacidade de aqueles veicularem os valores desta.

A prática interaccional que é a comunicação pedagógica vai assim privilegiar determinađos significados e determinadas orientações para o significado, enquanto outros significados e outras orientações são postergadas. A operatividade da selecção fundamenta-se no facto de o contexto pedagógico ser, também ele, regulado por uma distribuição diferenciada de poder e controlo entre transmissores e aquisidores, geradora de códigos dominantes e de códigos dominados.

$\mathrm{O}$ contexto pedagógico define assim aquilo que é legítimo associar e dizer e ao mesmo tempo aquilo

(2) Id., ibid., p. 327.

(3) BERNSTEIN, B (1977). Class, Codes and Control, Vol. 3 , Towards a Theory of Educational Transmissions. Routledge and Kegan Paul, London, pp. 79-84 que não é legítimo associar e dizer. Deste modo constitui-se um discurso específico. Este discurso comporta o discurso instrucional, isto é, a transmissão de conteúdos definidos pelo curriculum, e o discurso regulador, que é a forma que assumem «os princípios através dos quais as relações sociais de transmissão e aquisição são implantadas, mantidas, reproduzidas e legitimadas» $\left({ }^{4}\right)$. O discurso regulador, que é um discurso de ordem, é um dos modos sob que se pode materializar a dominância de um código sobre outro no contexto pedagógico. Em outro sentido falar-se-á de uma função de instrução, que consiste na transmissão de conhecimentos, capacidades e técnicas, em oposição a uma função de socialização, que consiste na transmissão de normas, valores e atitudes.

A linguagem verbal, ou melhor, linguagens verbais específicas surgem como meio privilegiado de actualização e constituição dos conteúdos escolares $\left({ }^{5}\right)$. Estando, como vimos, a configuração dos curricula associada a modalidades de cultura, aqueles procuram impor formas de comunicação congruentes.

\section{INSUCESSO E SELECÇÃO SOCIAL NA DISCIPLINA DE PORTUGUÊS}

Os participantes no seminário, distribuídos por cinco núcleos de Estágio Integrado đe Português-Inglês da Universidade do Minho, recolheram dados em cinco escolas secundárias dos distritos de Braga e Viana do Castelo, relativos a dezoito turmas (tantas quantos os professores participantes) do Curso Geral Unificado, num total de 485 alunos inquiridos, dos quais 218 (45\%) do sexo masculino e 267 (55\%) do sexo feminino (ver Quadro I). O

(4) PEDRO, E. R. (1982). O Discurso na Aula Uma análise sociolinguistica da prática escolar em Portugal. Ediçōes Rolim, Lisboa, p. 125.

(5) Esta afimação não significa o desprezo por outros meios e formas de hierarquizar valores e conhecimentos. É o caso da organização do espaço e do tempo pedagógicos, por exemplo. Acerca das hierarquias administrativas, de conhecimento $\mathrm{c}$ estatutárias, cf. FERNANDES, A.S. ( s. d.) «Socialização e Desenvolvimento dos Comportamentos Sociais», in PIRES, E. L., FERNANDES, A. S., LIMA, L. Noçöes de Sociologia da Educação. Ministério da Educaçāo c Universidade do Minho, fasc. quatro, pp. 1-12. 


\section{Quadro I}

Dados gerais relativos aos alunos estudados em cinco escolas secundárias dos distritos de Braga e de Viana do Castelo (1985)

\begin{tabular}{|c|c|c|c|c|c|}
\hline Ano & $\begin{array}{c}N^{N} \\
\text { de } \\
\text { Turnas }\end{array}$ & \multicolumn{2}{|c|}{ Alunos } & \multirow{2}{*}{$\begin{array}{c}\text { Média } \\
\text { Alunos/ } \\
\text { rrurmas }\end{array}$} & $\begin{array}{c}\text { Média } \\
\text { de } \\
\text { Idades }\end{array}$ \\
\cline { 1 - 3 } $7^{\circ}$ & 10 & 284 & 58,6 & 28,4 & 12,9 \\
$8^{\circ}$ & 4 & 106 & 21,8 & 26,5 & 14,2 \\
$9^{\circ}$ & 4 & 95 & 19,6 & 23,8 & 15,2 \\
Total & 18 & 485 & 100 & 26,9 & 13,6 \\
\hline
\end{tabular}

conjunto dos dados recolhidos reporta-se às turmas em que os professores estagiários leccionavam a disciplina de Português.

As fontes para obtenção dos dados foram as informações constantes das cadernetas escolares e dos dossiers dos directores de turma. Assim se obtiveram dados relativos ao ano de escolaridade, turma, sexo, idade, profissões do pai e da mãe e rendimento escolar em todas as disciplinas nos primeiro e segundo períodos lectivos de 1984/85. Pela impossibilidade de conhecer com exactidão as habilitações escolares dos pais, e muito menos os seus rendimentos, considerou-se como critério fundamental para a atribuição a cada aluno da respectiva "posição social» as profissōes do pai e da mãe. Mesmo assim pensamos ser este um critério de algum modo significativo, porque a partir dele se podem obter indicações sobre o capital cultural da família e até sobre o seu rendimento. Utilizámos um quadro de «posições sociais» elaborado pela Área de Análise Social e Organizacional da Educação da Universidade do Minho, que contempla quatro situações: "Posição Social I" - classe superior (profissões liberais, grandes industriais e comerciantes, altos funcionários, gestores de empresas, etc.); "Posição Social II" — classe média mais instruída (professores do ensino não superior, médios industriais e comerciantes, funcionários médios...); "Posição Social III" - classe média menos instruída (pequenos industriais e comerciantes, capatazes, encarregados de obras...); "Posição Social IV" - estrato operário e rural: trabalhadores manuais (operários não qualificados, trabalhadores rurais, funcionários auxiliares...). Sempre que possível e/ou necessário procurou-se considerar critérios complementares como habilitaçôes e local de residência.

O Gráfico 1 representa a distribuição dos alunos estudados por «posição social».

\section{Gráfico 1}

Distribuiçäo do número de alunos estudados pela respectiva "Posição Social"

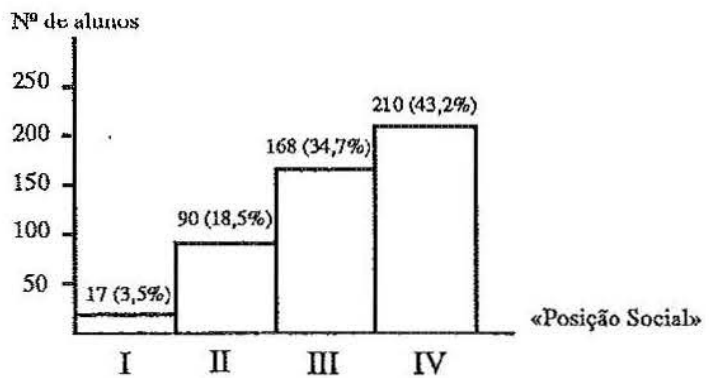

Tendo estes dados presentes procurou-se de seguida verificar como se comportavam as diferentes «posições sociais» em termos de sucesso/insucesso escolar na disciplina de Português. Utilizámos como indicador os níveis de classificação atribuídos aos alunos nos primeiro e segundo períodos lectivos. De acordo com os critérios vigentes no Ensino Secundário Unificađo, os níveis 1 e 2 classificam alunos insucedidos, e os níveis 3,4 e 5 alunos sucedidos.

No primeiro período foram registados 173 alunos $(35,6 \%)$ com os níveis 1 e 2 , e no segundo periodo $195(40,2 \%)$. Regista-se pois uma tendência para aumento dos níveis inferiores, que eventualmente as classificações do terceiro período poderiam vir a confirmar em definitivo, mas que o calendário de realização deste trabalho não permitiu apurar.

Em relação à média dos níveis de classificação atribuídos aos alunos da disciplina de Português, por «posição social», obtiveram-se os valores 3,3 , 2,8, 2,5 e 2,6 para, respectivamente, as «posições sociais» I, II, III e IV. Esta foi a mais importante das evidências empíricas detectadas, quer porque aponta para uma forte relação entre a «posição social» dos alunos e os níveis de classificação atingidos (quanto mais elevada é a «posição social» mais elevado é o nível de classificação), quer 
pelo seu valor pedagógico para a formação dos participantes $\left({ }^{6}\right)$.

Embora em termos de análise tenham sido consideradas quatro «posições sociais», os dados obtidos referentes aos nívcis de classificação đelimitam três grupos, correspondentes às «posições sociais» I, (3,3 como valor de classificação), II (2,8 como valor médio de classificação e III e IV (respectivamente com 2,5 e 2,6 de valor médio de classificação). A este propósito, atente-se no Gráfico 2 que se segue.

\section{Gráfico 2}

Média dos níveis de classificação atribuídos aos alunos na disciplina de Português ( $I^{o}$ e $2^{\underline{a}}$ Períodos) por "Posição Social".

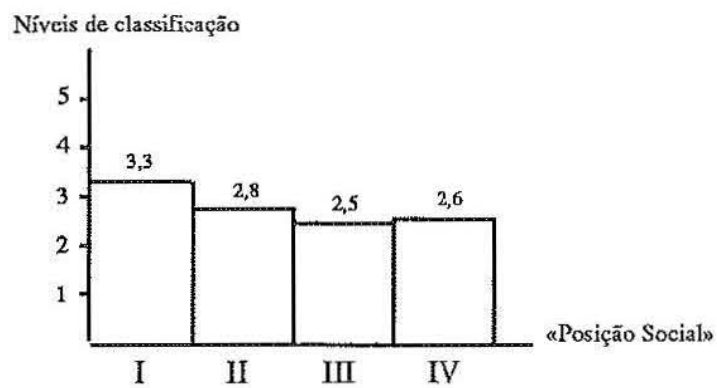

Em síntese, podemos concluir com alguma segurança pela distribuição diferenciada dos níveis de sucesso/insucesso dos alunos de Português. Os níveis de insucesso são, como vimos, significativamente elevados, de tal forma que configuram a disciplina como uma das mais selectivas no curriculum do Curso Geral Unificado. Refira-se que nas dczoito turmas estudadas o Português surge sempre, cmbora em posições variadas, no grupo das três disciplinas mais selectivas.

\section{DE UM DISCURSO CRÍTICO A UMA PRÁTICA LEGITIMADORA}

Num segundo momento de investigação, aos professores participantes no seminário foi distri-

(6) Dados relativos a outras disciplinas, analisados sob estas c outras perspectivas, são apresentados em «Insucesso Escolar em questăo», série de onze artigos da autoria dos docentes da Área de Análise Social c Organizacional da Educação da Universidade do Minto, publicados no Jornal de Notícias entre 29/1/85 e 9/4/85. buído um questionário com que se procurava avaliar a sua posição perante a organização do curriculum, a sua posição perante o significado dos conteúdos que leccionavam, as explicações possíveis para a selectividade da disciplina de Português e, ainda, a forma como modalizavam essa selectividade.

$O$ que se pretendia era, numa perspectiva de investigação piloto, tentar determinar a percepção que os inquiridos possuíam do curriculum como estrutura arbitrariamente organizada de conteúdos (7) e verificar, também, que aspectos eram considerados e valorizados na sua transmissão.

Os sujeitos inquiridos foram todos os dezoito professores estagiários participantes no scminário, sendo dezasseis do sexo feminino $(88,9 \%)$ e dois do sexo masculino $(11,1 \%)$, com idades compreendidas entre os 22 e os 31 anos, perfazendo uma média de idades de 24,9 . As suas habilitações académicas, comuns a todos, eram o quarto ano da Licenciatura em Ensino de Português-Inglês. Dez dos inquiridos $(55,6 \%)$ tinham experiência anterior à entrada no estágio, igual ou superior a três meses, e oito dos inquiridos $(44,4 \%)$ não possuíam qualquer experiência profissional antcrior.

Com o objeclivo acima rcferido, no questionário distribuido uma das alíncas solicitava o estabelecimento de uma relação de importância entre as disciplinas que constituem o curriculum do $8^{\circ}$ Ano de escolaridade. O Quadro II apresenta as posições médias obtidas por cada disciplina (os limites da escala cram 1 para a disciplina considerada mais importante e 11 para a considerada menos importante) na sua globalidade, primeiro, e depois distribuídas em função da existência ou não de experiência docente por parte dos inquiridos.

Algumas evidências: o modclo de organização curricular, na posição rclativa dos conteúdos, considerada a totalidade das respostas, caracteriza-se por uma forte insularidade entre as categorias constituídas pelos conteúdos que integram a componente académica e aqueles que constituem a componente não académica. Aqucla, no conjunto das respostas, aparece privilegiada e distinta relativamente a esta; por outro lado, estabelecem-se três grupos de disciplinas que se diferenciam: um

(7) A propósito desta noçäo e para o estabelecimento de uma relação com o conceito de «arbítrio cultural», cf. BOURDIEU, J., PASSERON, J. C. (1970). La Réproduction: éléments pour une théorie du système d'enseignement. Editions de Minuit, Paris. 
Quadro II

Relação de importância entre as disciplinas do $8^{\circ}$ Ano

\begin{tabular}{|c|c|c|c|c|c|c|c|}
\hline & \multirow{3}{*}{$\begin{array}{c}\text { Elenco oficial } \\
\text { das Disciplinas } \\
\text { do } 8^{\circ} \text { ano }\end{array}$} & \multicolumn{6}{|c|}{ Posição média de importância relativa } \\
\hline & & \multicolumn{2}{|c|}{$\begin{array}{l}\text { Total dos } \\
\text { inquiridos }\end{array}$} & \multicolumn{2}{|c|}{$\begin{array}{l}\text { Inquiridos com } \\
\text { experiência }\end{array}$} & \multicolumn{2}{|c|}{$\begin{array}{l}\text { Inquiridos sem } \\
\text { experiência }\end{array}$} \\
\hline & & Média & Posição & Média & Posição & Média & Posição \\
\hline \multirow{7}{*}{ 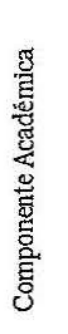 } & Português & 1,2 & $1 a$. & 1,3 & 1a. & 1,0 & 1a. \\
\hline & Línguas Estrangeiras & 4,2 & $3 a$. & 4,1 & $3 a$. & 4,3 & $3 a$. \\
\hline & Matemática & 2,9 & 2a. & 3,2 & 2a. & 2,5 & $2 a$. \\
\hline & História & 4,7 & $4 a$. & 4,6 & $4 a$. & 4,8 & 5a. \\
\hline & Geografia & 6,4 & $6 a$. & 6,7 & $7 \mathrm{a}$. & 6,0 & $6 a$. \\
\hline & Biologia & 5,8 & $5 a$. & 6,8 & 9a. & 4,6 & $4 a$. \\
\hline & Ciĉncias Físico-Químicas & 6,4 & $6 a$. & 6,7 & $7 a$. & 6,0 & 6а. \\
\hline \multirow{4}{*}{ 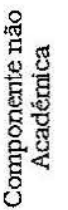 } & Educação Visual & 7,2 & $9 a$. & 6,3 & $6 a$. & 8,2 & 9a. \\
\hline & Trabalhos Oficinais & 8,3 & $10 a$. & 7,2 & $10 \mathrm{a}$. & 9,8 & $10 a$. \\
\hline & Educação Física & 6,9 & $8 a$. & 6,0 & $5 a$. & 8,1 & $8 \mathrm{a}$. \\
\hline & Religião e Moral & 10,4 & 11a. & 10,6 & $11 \mathrm{a}$. & 10,1 & $11 a$. \\
\hline
\end{tabular}

primeiro constituído pelas disciplinas tradicionalmente consideradas mais importantes, um segundo pelas restantes disciplinas de modelo humanístico e um terceiro composto por disciplinas relacionadas com as ciências exactas e da natureza.

Se considerarmos apcnas as respostas dos inquiridos sem experiĉncia profissional anterior vemos que o princípio de classificação que regula a relação cntre as componentes académica e não académica é ainda mais forte. Como mais marcada é dentro daquela a distinção entre o Português e a Matemática e as restantes disciplinas. Para os inquiridos com prática de ensino anterior as coisas apresentam-se difcrentes cm alguns sentidos. Não só a separação nítida cntre componente académica e não académica deixa de existir, como a posição do Português e da Matemática não aparece tão evidencia$\mathrm{da}$, embora continuem a ocupar as duas primeiras posições.

A posição em que surgé a đisciplina de Português é notável. Tão só três inquiridos não a consideram a mais importante; dois deles consideram-na como a segunda disciplina mais relevante do curriculum e um a terceira. Curiosamente os três «desviantes» encontram-se entre os indivíduos com prática profissional anterior ao início do estágio.

As razões explicativas destes factos deverão possivelmente ser procuradas no papel socializador conferido à disciplina e no próprio poder de convencimento da tradição da organização curricular $\left.{ }^{8}\right)$, poder a realçar sobretudo se tivermos em conta a formação $\mathrm{cm}$ ciências da educação dos inquiridos.

Em todo o caso seria interessante avaliar em que medida o peso atribuído ao Português se pode relacionar com o facto do questionário se dirigir apenas a professores que leccionavam aquela disciplina. Esta situação pode em nosso entender, por outro lado, explicar, ao menos parcialmente, a posição

(8) À disciplina de Português têm os curricula concedido um papel relevante desde a criação do Liceu no regime liberal até aos nosson dias. Ela integrou scmpre a comporente académica tradicional, uma das constantes apontadas em LIMA, L. C. (1984), «Dos Liceus às Escolas Secundárias: Constantes e Inovaçũo de Percursos. Tellus (Especial), pp. 45-65. 
conferida à Língua Estrangeira (recorde-se que estes professores leccionavam também a disciplina de Inglês).

No sentido de averiguar das razões do posicionamento da disciplina solicilámos a explicitação dos critérios que o justificariam.

As respostas obtidas foram organizadas segundo uma tipologia em que considerámos, para os critérios apresentados, uma componente socializadora - que releva na disciplina os aspectos concernentes ao scu funcionamento como agente de integração social —, uma componente instrucional/ instrumental - a disciplina é encarada como transmissora de conteúdos e capacidades que funcionam como suportes para outros sabcres - e uma componente estimuladora - a disciplina é vista como despoletadora do desenvolvimento dos alunos.

O Quadro III dá conta do modo como se distribuiram os resultados. dora, que atinge o seu nível mais baixo no conjunto das categorias consideradas.

Pedia ainda o questionário que se organizasse gradativamente um conjunto de possiveis razões explicativas do insucesso na disciplina de Português. Observemos, no Quadro IV, os dados obtidos.

Se atendermos aos resultados globais, uma primeira constatação é a de que o leque das posições não é muito alargado. Mesmo assim parece ser possível constituir três grupos assim organizados: um primeiro grupo, de que participam razões de tipo metodológico e sociológico - primeira e segunda razōes; um segundo grupo que comporta razões relacionadas com o funcionamento do sistema de ensino - razões terceira e sexta; e um último grupo, relativo às capacidades individuais - razão úlima.

Com uma muito pequena alteração, a posição relativa das razões apresentadas, se considerarmos

Quadro III

Classificação dos critérios apresentados para justificar a primeira posiçāo que os inquiridos airibuiram ao Português

\begin{tabular}{|l|c|c|c|}
\hline \multirow{2}{*}{$\begin{array}{l}\text { COMPONENTES DO } \\
\text { ACTO EDUCATIVO }\end{array}$} & \multicolumn{3}{|c|}{ RESPOSTAS OBTIDAS (\%) } \\
\cline { 2 - 4 } & $\begin{array}{c}\text { Total } \\
\text { dos inquiridos }\end{array}$ & $\begin{array}{c}\text { Inquiridos com } \\
\text { experiência }\end{array}$ & $\begin{array}{c}\text { Inquiridos sem } \\
\text { experiência }\end{array}$ \\
\hline $\begin{array}{l}\text { COMPONENTE } \\
\text { SOCIALIZADORA }\end{array}$ & 32.5 & 22.7 & 42.9 \\
\hline $\begin{array}{l}\text { COMPONENTE } \\
\text { INSTRUCIONAL/NSTRUMENTAL }\end{array}$ & 60.4 & 68.2 & 52.5 \\
\hline $\begin{array}{l}\text { COMPONENTE } \\
\text { ESTIMULADORA }\end{array}$ & 7.0 & 9.1 & 4.8 \\
\hline TOTAL & 99.9 & 100 & 100.2 \\
\hline
\end{tabular}

Considerado o total das respostas, mais de $60 \%$ enfatizam a importância da disciplina relacionando-a com o seu valor instrucional/instrumental. $O$ número das respostas que revelam o seu valor a partir da consideração da sua força socializadora é também ele significativo $(32 ; 5 \%)$.

Tendo presente a variável experiĉncia profissional, constata-se que entre os inquiridos sem prática de ensino anterior há um reforço acentuado da valorizaçāo na disciplina da vertente socializadora em detrimento da instrucional/instrumental, que mantém porém a primeira posição, e da estimula- a experiência profissional anterior, mantém-se. Mas a consideração da variável fornece dados interessantes. Assim, para os inquiridos com prática anterior de ensino os programas aparecem com muito maior importância (em terceiro lugar) como razão de insucesso do que para os restantes inquiridos (em último lugar). Também para aqueles que tinham já anteriormente leccionado, a origem social dos alunos surge como razão mais provável de reprovação. Para os indivíduos sem experiência de ensino anterior, a formação académica dos professores, mais do que para os outros, parece ser 
Quadro IV

Razōes explicativas do insucesso na disciplina de Português apresentadas pelos professoresinquiridos

\begin{tabular}{|c|c|c|c|c|c|c|}
\hline \multirow{3}{*}{$\begin{array}{c}\text { RAZÕES } \\
\text { EXPLICATIVAS }\end{array}$} & \multicolumn{6}{|c|}{ POSIÇÃO MÉDIA DE IMPORTÂNCIA RELATTVA } \\
\hline & \multicolumn{2}{|c|}{ Total inquiridos } & \multicolumn{2}{|c|}{ Inquir. $c /$ experiência } & \multicolumn{2}{|c|}{ Inquir. s/ experiência } \\
\hline & Média & Posição & Média & Posição & Média & Posição \\
\hline Os métodos utilizados & 2,6 & $1 \mathrm{a}$. & 2,5 & 1a. & 2,8 & 1a. \\
\hline A origem social dos alunos & 2,9 & $2 a$. & 2,7 & $2 a$. & 3,4 & 2a. \\
\hline $\begin{array}{l}\text { A preparação anterior } \\
\text { dos alunos }\end{array}$ & 3,8 & $3 a$. & 3,8 & $4 a$. & 3,8 & 4a. \\
\hline $\begin{array}{l}\text { A formação académica } \\
\text { dos professores }\end{array}$ & 4,2 & 4a. & 4,6 & 5a. & 3,6 & 3a. \\
\hline Os programas & 4,4 & 5a. & 3,7 & 3a. & 5,5 & 7a. \\
\hline $\begin{array}{l}\text { A formação profissional } \\
\text { dos professores }\end{array}$ & 4,4 & 5a. & 4,7 & $6 a$. & 4,1 & $5 a$. \\
\hline $\begin{array}{l}\text { As capacidades individuais } \\
\text { dos alunos }\end{array}$ & 5,0 & 7a. & 5,3 & 7a. & 4,8 & $6 \mathrm{a}$. \\
\hline
\end{tabular}

hipótese explicativa, com algum peso, do insucesso. As capacidades individuais dos alunos são consideradas quase irrelevantes em ambas as categorias $\left({ }^{9}\right)$.

Conhecida a posição dos inquiridos sobre as possíveis razões explicativas do insucesso na sua disciplina, tornava-se importante saber quais os domínios considerados decisivos na definição do sucesso/insucesso dos alunos. Distribuímos um inventário de critérios e pedimos aos participantes no seminário que os organizassem por ordem de importância relativo. Vejamos os resultados obtidos (Quadro V).

A posição relativa dos critérios mantém-se, nas tiês catcgorias consideradas, significativamente estável. Anotemos, entretanto, alguns pormenores. Os critérios considerados mais pertinentes respei-

(9) $\Lambda$ este facto poderá não ser alheia a circunstância de os inquiridos se encontrarem a frequentar um Seminário de Sociologia da Educação tam à competência comunicativa demonstrada pelos alunos e ao domínio dos conteúdos disciplinares; os restantes critérios são considerados menos relevantes, ou quase não são considerados (veja-se o caso dos comportamentos disciplinares). Repare-se também na posição dominante ocupada pelo critério relativo à competência de comunicação escrita frente à competência de comunicação oral.

Atente-se finalmente no facto dos dados constantes dos Quadros III e V se apresentarem congruentes. Assim, os três primeiros critérios registados no Quadro V são relacionáveis com a componente instrucional/instrumental, ao passo que os critérios restantes são passíveis de associação com a componente socializadora.

Porém, se considerarmos novamente os dados do Quadro V (critérios considerados decisivos para aprovação/reprovação) e os relacionarmos com os do Quadro IV (razões explicativas do elevado índice do insucesso empiricamente constatado $\mathrm{cm}$ 
Quadro V

Critérios considerados decisivos para o insucesso

dosalunos de Português

\begin{tabular}{|c|c|c|c|c|c|c|}
\hline \multirow{3}{*}{ CRITÉRIOS } & \multicolumn{6}{|c|}{ POSIÇÃO MÉDIA DE IMPORTÂNCIA RELATIVA } \\
\hline & \multicolumn{2}{|c|}{ Total inquiridos } & \multicolumn{2}{|c|}{ Inquir. c/ experiência } & \multicolumn{2}{|c|}{ Inquir. s/ experiência } \\
\hline & Média & Posição & Média & Posição & Média & Posição \\
\hline $\begin{array}{l}\text { Utilização deficiente } \\
\text { da língua na comunicacão } \\
\text { escrita }\end{array}$ & 2,1 & la. & 1,9 & $1 \mathrm{a}$. & 2,3 & $1 \mathrm{a}$. \\
\hline $\begin{array}{l}\text { Conhecimento insufi- } \\
\text { ciente dos conteúdos } \\
\text { programáticos }\end{array}$ & 2,5 & $2 a$. & 2,3 & $2 a$. & 2,9 & $2 a$. \\
\hline $\begin{array}{l}\text { Utilização defíciente } \\
\text { da língua na comunicação } \\
\text { oral }\end{array}$ & 2,8 & 3a. & 2,5 & $3 a$. & 3,1 & 3a. \\
\hline $\begin{array}{l}\text { Desconhecimento de } \\
\text { dados culturais pres- } \\
\text { supostos ou exigidos } \\
\text { pelos programas }\end{array}$ & 4,2 & 4a. & 4,3 & 4a. & 4,1 & $5 a$. \\
\hline $\begin{array}{l}\text { Não participação nos } \\
\text { trabalhos escolares }\end{array}$ & 4,3 & $5 a$. & 4,5 & $5 a$. & 4,0 & $4 a$. \\
\hline Indisciplina & 5,1 & $6 a$. & 5,4 & $6 a$. & 4,6 & $6 a$. \\
\hline
\end{tabular}

2.) obteremos, porventura, aquela que se nos afigura como a mais fecunda das «conclusões» deste trabalho. Recorde-se que os inquiridos atribuiram à origem social dos alunos uma importância muito significativa enquanto razão explicativa do insucesso, revelando deste modo uma certa «sensibilidade sociológica» que o seu discurso claramente traduz. Contudo, quando solicitados a explicitar os critérios que utilizam para a aprovação/reprovação dos alunos, os professores valorizam sobrctudo aqueles que mais directamente se relacionam com a componente instrucional/instrumental. Há pois uma contradição entre um discurso pedagógico que integra uma dimensão sociológica e uma «prática» baseada em critérios não coincidentes com os princípios que fundamen- tam aquele discurso $\left({ }^{10}\right)$; pelo contrário, valorizam-se critérios congruentes com a componente instrucional/instrumental.

A um discurso indicador de uma tomada de posição crítica perante uma realidade, parecc contrapor-se uma prática legitimadora dessa mesma realidade $\left({ }^{11}\right)$.

(10) Não se trata aqui de uma prática observada, mas de uma prática cujo conbecimento é mediatizado pelo discurso.

(11) Esta oposição sugerc-nos a distinção entre «contexto educativo» e «contexto de professores» operada por KEDDIE, N. «O Saber na Sala de Aulas», in GRÁCIO, S. e STOLR, S. (1982) Sociologia da Educação-II. A Consiruçâo Social das Práticas Educativas. Livros Horizonte, Lisboa, pp. 205-244. 


\section{COMENTÁRIOS E NOTAS PARA IN- VESTIGAÇÃO}

Não se tratando aqui de apresentar conclusões que, como já referimos, o âmbito e o propósito do trabalho desaconselham, não gostaríamos, porém, de o terminar sem avançar alguns comentários e eventuais pistas de análise que dele nos parecem decorrer. Trata-se sobretudo de colocar perguntas que só trabalhos posteriores poderão ensaiar responder. Retomando o comentário realizado no úlimo momento do capítulo anterior, questões pertinentes parecem emergir. $O$ que impede estes professores de terem uma prática pedagógica concordante com o seu discurso de contornos problematizadores?

Será que o desejo de conservação do elevado «status» da disciplina de Português e o assumir da sua função de seleç̧ão social se sobrepõem, em termos de prática pedagógica, a uma análise inovadora e às consequências que da sua actualização decorreriam? Ou serão as orientações programáticas e didácticas dominantes que impedem esta última? Em que medida a dimensão organizacional da escola dificulta a inovação? Em suma, que razões poderão explicar a dificuldade de operacionalizar formas de discriminação positiva dos alunos das «posições sociais» mais baixas?

A resposta a estas perguntas exigiria que, a partir dos dados aqui apresentados, outros estudos e investigações fossem empreendidas. Procuramos seguidamente inventariar alguns temas e problemas que se nos afiguram como mais interessantes e cujo contributo poderá ser o de, eventualmente, fomecer pistas e sugestões para investigação.

Desde logo seria oportuno aplicar o mesmo tipo de questionário a professores com formação académica e pedagógica diferenciada, de categorias profissionais distintas, variando a idade, o sexo, a origem social, o tempo de serviço, etc. Em que medida variariam as suas propostas de organização curricular, os critérios valorizados, as razõcs explicativas fornecidas? E a importância cimcira da disciplina đe Português, manter-se-ia se a docentes de outras disciplinas fosse solicilada uma proposta de organização curricular por importância das respectivas disciplinas? Será que existem relações cntre a «origem social» do professor, a «posição social» dos alunos, e as modalidades e os resultados de avaliação?

Em turmas tendencialmente homogéneas quanto à «posição social» como se comportam os alunos de «posição social» distinta da dominante? As rclações aqui estabelecidas entre a «posição social» dos alunos e o seu aproveitamento manter-se-ão, ou modificar-se-ão sensivelmente, consoante as escolas são predominantemente urbanas ou integram sobretudo alunos provenientes de meios rurais?

Que conclusões poderiam vir a ser extraídas do estudo dos índices de insucesso na disciplina de Português, ao longo dos diversos anos de escolaridade, e em diferentes escolas? Será que esses dados, aliados ao estudo e ao acompanhamento do percurso escolar de diferentes alunos de Português, sugeririam uma tendência para a concentração dos níveis do insucesso em certos anos de escolaridade, períodos lectivos, ou outras fases consideradas críticas? E quanto à avaliação, qual o papel desempenhado pelas provas escritas, de resto dominantes na avaliação đa disciplina? Uma prática alternativa, ou combinada, que resultados poderia indiciar? Como reagiriam os professores de Português (e de outras disciplinas) à possibilidade dc passagem automálica de todos os alunos durante a escolaridade obrigatória, c que estratégias passariam a actualizar?

Qual o papel desempenhado pelos programas e pelos seus conteúdos, pelos valores e linguagens expressos nos livros de textos, e pelo predomínio da componente literária na disciplina, em termos de insucesso e selcç̧ão social dos alunos?

Dos diferentes discursos dos diferentes alunos, e das suas também diferentes práticas interaccionais, o que é que os docentes consideram adcquado, passível de ser valorizado? Ou seja, como é realizada a selecção das práticas discursivas e dos conhecimentos considerados social e academicamente úteis, no universo da sala de aula? Ou ainda, de que forma(s) é que a organização da linguagem serve a linguagem como organizaçăo?

E à luz de estudos recentemente realizados, qual será o papel do Português na transmissão e reprodução de símbolos e rituais (verbais e não verbais), e de que símbolos e rituais $\left({ }^{12}\right)$ ? Que eventuais

(12) Cf. a este propósito o recente trabalho de McI.AREN, $P$. (1986), Schooling as a Ritual Performance. Towards a political economy of educational symbols and gestures. Routledge and Kegan Paut, Londion. 
conflitos podem emergir daí em relação às subculturas juvenis dos alunos e a outras subculturas de diferente matriz? E, nestes casos, será o seu insucesso uma incapacidade ou verdadeiramente uma resistência $\left({ }^{13}\right)$ ?

Estas questões sugerem a necessidade de se empreenderem estudos de carácter interdisciplinar, integrando as perspectivas sociológica, psicológica, metodológica, organizacional, etc., no quadro da formação de professores.

A consideração dos comportamentos dos alunos perante certas disciplinas, como ponto de partida para o estudo das percepções que os professores têm desses comportamentos e dos seus próprios papéis, da importância dos conteúdos que leccionam e das estratégias que actualizam, parece constituir um percurso interessante e em boa parte por explorar.

Tal percurso é especialmente congruente com uma estratégia de formação - investigação acção capaz de promover a efectiva integração das diversas ciências da educação, de possibilitar uma avaliação dos modelos de formação adoptados, e de cleger os estágios pedagógicos como arena privilegiada de investigação e de intervenção.

\section{BIBLIOGRAFIA CITADA}

BERNSTEIN, B. (1977) - Class, Codes and Control, Vol. 3: Towards a Theory of Educational Transmissions, Routledge and Kegan Paul, London.

BERNSTEIN, B. (1981) «Codes, modalities, and the process of cultural reproduction: A model». Language and Society, (10)

BOURDIEU, J., PASSERON, J. C. (1970)-La Reproduction: éléments pour une théorie du sysième d'enseignement, Editions de Minuit, Paris.

FERNANDES, A. S. (s. d.) - «Socialização e desenvolvimento dos comportamentos sociais» in PIRES, E. L., FERNANDES, A. S., LIMA, L., Noções de Sociologia de Educação, Ministério da Educação e Universidade do Minho, fasc. quatro.

KEDDIE, N. (1982) - «O saber na sala de aulas» in GRÁCIO, S. e STOER, S., Sociologia da Educação
- II. A Construção Social das Práticas Educativas, Livros Horizonte, Lisboa.

LIMA, L. (1984) $\_$Dos Liceus às escolas secundárias: Constantes e Inovação de Pcrcurso». Tellus (especial).

MCLAREN, P. (1986) - Schooling as a Ritual Performance. Towards a political economy of educaiional symbols and gestures. Routledge and Kegan Paul, London.

PEDRO, E. R. (1982) - O discurso na aula. Uma análise sociolinguística da prática escolar em Portugal. Ediçōes Rolim, Lisboa.

WILLIS, P. E. (1983) - Learning to Labour. How working class kids get working class jobs, Gower.

\section{RESUMO}

Neste texto apresentam-se e analisam-se dados de investigação obtidos no decurso de um Seminário sobre "Cultura, Linguagem e Curriculum» que os autores orientaram na Universidade do Minho em 1985.

A análise dos dados recolhidos permitiu apurar o seguinte:

- A disciplina de Português tem um carácter duplamente selectivo: primeiro, no sentido em que se configura como uma das disciplinas em que a taxa de insucesso é mais elevada; depois, porque a selecçäo que assim se opera é socialmente marcada;

- $A$ concepção dominante do curriculum privilegia a componente académica (e dentro desta, o Português) em detrimento da componente não académica;

- A justificação do posicionamento do Português assenta na valorização das componentes instrucionall linstrumental e socializadora;

- A explicação para o insucesso é cometida sobretudo a factores sociológicos e metodológicos;

- Os critérios considerados mais relevantes para a definição do sucesso têm a ver com a competência comunicativa manifestada e como domínio dos conteúdos programáticos.

A reflexäo sobre estes dados tornou sobretudo evidente uma contradiçăo entre um discurso «pedagógico» $\varepsilon$ uma «prática» fundada em princípios não congruentes com aquele discurso.

Os ausores, assinalando o carácter exploratório que atribuem a este trabalho, avançam algumas hipóteses explicativas para of acto consiatado $e$, a partir dos dados estudados, fornecem pistas e sugestôes de investigação.

(13) Acerca desta problemática cf. WILLIS, P. E. (1983) Learning to Labour. How working class kids get working class jobs, Gower. 


\begin{abstract}
In this paper, research data are introduced and analized on the basis of a Seminar organized in Minho University, in 1985, under the title "Culture, Language and Curriculum».

The data collected revealed that:

-As a subject in the school curriculum, Portuguese (language and literature) is one of the most selective subjects: not only because it is where most students fail, but also because the students who fail belong, in its majority, to the lower social classes;

- For the teachers studied, the most important subjects in the school curriculum are the academic ones, specially Portuguese (language and literature);
\end{abstract}

-That judgment was based on the importance of the instructional and socializing aspects of the subject;

-The given reasons for explaining students' failure in the subject were predominantely of sociological and methodological character;

- The main criteria pointed out by the teachers to support those students who succeeded were the communicative competence and the knowledge of the main contents of the subject expressed in the official programme.

It was found a contradiction between the teachers' "pedagogical» discourse and their school practice, which was not congruent with the orientation they had expressed before.

Some explanation and some research problems to be studied in the future are advanced by the authors. 